\title{
Isolation and Characterization of Enterococcus faecalis-Infecting Bacteriophages From Different Cheese Types
}

\author{
Beatriz del Rio ${ }^{1,2}$, Esther Sánchez-Llana1 ${ }^{1}$, Noelia Martínez¹, María Fernández1,2, \\ Victor Ladero ${ }^{1,2 *}$ and Miguel A. Alvarez ${ }^{1,2}$ \\ ' Department of Technology and Biotechnology of Dairy Products, Dairy Research Institute, IPLA-CSIC, Villaviciosa, Spain, \\ ${ }^{2}$ Molecular Microbiology Group, Instituto de Investigación Sanitaria del Principado de Asturias (ISPA), Oviedo, Spain
}

OPEN ACCESS

Edited by:

Fausto Gardini,

University of Bologna, Italy

Reviewed by:

Peter Pristas,

Pavol Jozef Šafárik University

in Košice, Slovakia

Giovanna E. Felis,

University of Verona, Italy

*Correspondence:

Victor Ladero

ladero@ipla.csic.es

Specialty section:

This article was submitted to

Food Microbiology,

a section of the journal

Frontiers in Microbiology

Received: 06 August 2020 Accepted: 09 December 2020

Published: 08 January 2021

Citation:

del Rio B, Sánchez-Llana E, Martínez N, Fernández M, Ladero V

and Alvarez MA (2021) Isolation

and Characterization of Enterococcus

faecalis-Infecting Bacteriophages

From Different Cheese Types.

Front. Microbiol. 11:592172.

doi: 10.3389/fmicb.2020.592172
Enterococci are a diverse group of Gram-positive, lactic acid bacteria (LAB). They are found in many environments, including fermented foods, in which they could constitute a health threat since they produce biogenic amines, which consumption can lead to intoxication. Moreover, enterococci has also emerged as an important hospitalacquired pathogens via its acquisition of antimicrobial resistance. Bacteriophages possess features that make them optimal biotechnological weapons for controlling bacterial growth in disease and food spoilage contexts. However, no silver bullet bacteriophage exists that can eliminate all the undesirable bacteria in a complex environment. Rather, a combination of phages with different host ranges would be required which implies the need for large collections of diverse phages. This work reports the isolation of several Enterococcus faecalis-infecting bacteriophages from different types of cheese, along with the range of $E$. faecalis strains of diverse origin (from dairy to clinical environments) they are able to infect. The isolated phages showed a large diversity regarding the number and origin of strains they infect. Some of these phages were subjected to morphological and genomic characterization which confirmed their diversity and showed they belong to different families and genera. The present findings increase the potential arsenal for the bacteriophage-based biocontrol of harmful E. faecalis populations.

Keywords: bacteriophage, genome characterization, cheese, Enterococcus faecalis, lactic acid bacteria

\section{INTRODUCTION}

The enterococci are a diverse group of Gram-positive belonging to the lactic acid bacteria (LAB) group. They are found in many environments, including the human gut where they normally exist as commensal microorganisms, although over the last 20 years they have emerged as important hospital-acquired pathogens through the acquisition of antimicrobial resistance (Torres et al., 2018). Nonetheless, they still play an important role in the production of fermented foods and some strains have even been proposed as probiotics (Foulquie Moreno et al., 2006). The presence of enterococci in different foods reflects their resistance to adverse environmental conditions: they can grow under aerobic and anaerobic conditions, over wide ranges of $\mathrm{pH}$ and temperature, 
and even in the presence of high salt concentrations conditions commonly encountered in food production and storage (Foulquie Moreno et al., 2006). Moreover, they can even survive pasteurization (Ladero et al., 2011).

These bacteria, however, also improve the microbiological safety of dairy products. For example, many strains of enterococci, especially those of Enterococcus faecium and Enterococcus faecalis, produce bacteriocins against foodborne pathogens such as Listeria monocytogenes (Khan et al., 2010). They also contribute to their organoleptic characteristics, especially those of traditional Mediterranean cheeses (Ogier and Serror, 2008). A variety of proteolytic enzymes involved in casein degradation and amino acid metabolism, plus lipolytic and citrate-degrading enzymes found in enterococci strains contribute to the unique taste and flavor of each (Giraffa, 2003). Unfortunately, these bacteria may also produce undesirable biogenic amines (BAs) such as tyramine and putrescine (Ladero et al., 2010b, 2012a; Linares et al., 2011). Indeed, the production of these two BAs is a species-specific trait of E. faecalis (Ladero et al., 2012b). The consumption of foods with high content of these BAs can lead to headaches, migraines and hypertension (Ladero et al., 2010a; Wunderlichová et al., 2014). Recent studies have also shown tyramine may be genotoxic for intestinal cells (del Rio et al., 2018), and confirm tyramine and putrescine to have cytotoxic effects (Linares et al., 2016; del Rio et al., 2019a).

E. faecalis enters the cheese-making process either directly via the milk, as a contaminant of water, or via the cheese manufacturing and processing equipment (Giraffa, 2003). The capacity of these bacteria to resist the harsh conditions of the cheese-making environment, plus their ability to survive pasteurization, make it difficult to reduce their numbers without negatively affecting those of desirable LAB species useful in cheese production and ripening (Novella-Rodriguez et al., 2002; Ladero et al., 2011). Methods that specifically target E. faecalis, without affecting other LAB species present in the cheese matrix, are therefore needed.

In recent years, bacteriophages, i.e., viruses that specifically kill bacteria, have appeared as new biotechnological tools for reducing the population of specific foodborne pathogens and spoilage microorganisms (Garcia et al., 2008; Moye et al., 2018). They have even been studied as a means of reducing the population of BA-producing bacteria in foods, and consequently keeping the BA concentration at safer levels (Ladero et al., 2016a; Yamaki et al., 2018). Phages, as natural predators of the bacteria they infect, possess various characteristics that made them optimal biotechnological weapons to control bacterial population growth (Hesse and Adhya, 2019). They are harmless to humans, animals and plants, can resist the harsh environmental conditions of food processing, are relatively cheap and easy to isolate and propagate and, since they are self-replicating, only small doses are needed. Moreover, they are self-limiting; they can only multiply if the host is present (Sillankorva et al., 2012; Fernandez et al., 2017). However, there is no single type of phage that can infect and eliminate all the undesirable bacterial species found in cheese. This is certainly true if the target belongs to the LAB group. The phages that infect these species usually have very narrow host ranges, sometimes even just a single strain (Kot et al., 2014; Martínez et al., 2016). To be an effective technology, combinations of phages with different characteristics and different host ranges would need to be used.

Currently, few E. faecalis phages have been described and characterized at the genomic and functional level; many more must be investigated if they are to be used as a means of reducing BA in dairy products (Bolocan et al., 2019). The present work reports the isolation of $E$. faecalis-infecting bacteriophages from different cheeses, and the E. faecalis strains from dairy and clinical environments that they are able to infect. A sample of these phages based on their host ranges was selected for morphological and genomic characterization.

\section{MATERIALS AND METHODS}

\section{Material, Bacterial Strains, and Culture Conditions}

Unless otherwise stated, all the reagents used in this work were purchased from Sigma-Aldrich (Spain). Sixty cheese samples belonging to nine cheese types, purchased at different markets over a 3-year period in Asturias (Spain), were used as a source of bacteriophages (Table 1). Different E. faecalis strains (15a, 19a, 23a, 52c, 63c, CECT795, V583 and CECT481 ${ }^{\mathrm{T}}$ ) of different origin were used as potential hosts in phage screening (Table 2). To determine the host range of isolated phages, additional E. faecalis strains were employed (Table 2). All bacterial strains were grown in M17 broth (Oxoid, Spain) supplemented with 0.5 glucose (GM17) without aeration. For phage enrichment cultures and host determination assays, the culture medium was supplemented with $10 \mathrm{mM} \mathrm{Ca}\left(\mathrm{NO}_{3}\right)_{2}$ and $10 \mathrm{mM} \mathrm{Mg}_{2} \mathrm{SO}_{4}$ (CMGM17). Phage titers were determined in double-layer agar plates, mixing $100 \mu \mathrm{l}$ of serial dilutions of the phage suspensions in $\mathrm{SM}$ buffer $\left(20 \mathrm{mM}\right.$ Tris- $\mathrm{HCl} \mathrm{pH} 7.5,1 \mathrm{mM} \mathrm{Mg} \mathrm{SO}_{4}, 100 \mathrm{mM}$ $\mathrm{NaCl}$ ) with $100 \mu \mathrm{l}$ of an overnight culture of the target host strain. Plates were incubated at $30^{\circ} \mathrm{C}$ for $18 \mathrm{~h}$ and the resulting plaques counted.

\begin{tabular}{llcc}
\hline TABLE 1 | Phage screening results. & & \\
\hline Cheese variety & Milk treatment & $\begin{array}{c}\text { Number of } \\
\text { samples } \\
\text { screened }\end{array}$ & Isolated phages \\
\hline Cabrales & Raw & 16 & $141,152,153,155$, \\
Emmental & Pasteurized & 10 & $158,159,160,161$ \\
Sheep milk cheese & Raw/Pasteurized & 8 & 143,146 \\
Blue-veined & Pasteurized & 8 & 156,157 \\
Boffard & Raw & 7 & $142,144,145,150$, \\
Gamoneu & Raw & 4 & 151,153 \\
Zamorano & Raw & 3 & 140 \\
Artisanal & Pasteurized & 2 & $147,148,149$ \\
Goat milk cheese & Raw/Pasteurized & 2 & 23 \\
Total & & 60 & Q69 \\
& & & 23
\end{tabular}


TABLE 2 | Enterococcus faecalis strains used in the initial screening and to determine the isolated bacteriophages host ranges.

\begin{tabular}{|c|c|c|c|}
\hline E. faecalis strains & Origin & Use & References/collection \\
\hline CECT481 ${ }^{\top}$ & Type strain & Screening & CECT \\
\hline $15 a$ & Dairy & Screening & Ladero et al., 2012b \\
\hline $18 a$ & Dairy & Host range & Ladero et al., 2012b \\
\hline $19 a$ & Dairy & Screening & Ladero et al., 2012b \\
\hline $23 a$ & Dairy & Screening & Ladero et al., 2012b \\
\hline $28 a$ & Dairy & Host range & Ladero et al., 2012b \\
\hline $52 c$ & Dairy & Screening & Ladero et al., 2012b \\
\hline $54 c$ & Dairy & Host range & Ladero et al., 2012b \\
\hline $57 c$ & Dairy & Host range & Ladero et al., 2012b \\
\hline $63 c$ & Dairy & Screening & Ladero et al., 2012b \\
\hline BA62 & Dairy & Host range & Ladero et al., 2012b \\
\hline BA64 & Dairy & Host range & Ladero et al., 2012b \\
\hline CECT 4039 & Dairy & Host range & CECT \\
\hline V61 & Dairy & Host range & Ladero et al., 2012b \\
\hline V63 & Dairy & Host range & Ladero et al., 2012b \\
\hline LMG20645 & Meat & Host range & LMG \\
\hline LMG12161 & Meat & Host range & LMG \\
\hline CECT795 & Human & Host range & CECT \\
\hline CECT4176 & Human & Host range & CECT \\
\hline HFS25 & Human & Host range & Ladero et al., 2009 \\
\hline HFS57 & Human & Host range & Ladero et al., 2009 \\
\hline HFS59 & Human & Host range & Ladero et al., 2009 \\
\hline HFS62 & Human & Host range & Ladero et al., 2009 \\
\hline HFS66 & Human & Host range & Ladero et al., 2009 \\
\hline HFS69 & Human & Host range & Ladero et al., 2009 \\
\hline $\mathrm{JH} 2-2$ & Clinical & Host range & Giard et al., 1996 \\
\hline V583 & Clinical & Screening & Paulsen et al., 2003 \\
\hline
\end{tabular}

CECT, Colección Española de Cultivos Tipo.

LMG, Laboratorium voor Microbiologie.

\section{Isolation of $E$. faecalis Bacteriophages From Cheese}

Phages were isolated from the cheeses by enrichment culture as previously described (Ladero et al., 2016a). Briefly, $1 \mathrm{~g}$ of each cheese sample was homogenized in $9 \mathrm{ml}$ of $2 \%$ sodium citrate in a Lab-Blender 400 stomacher (Seward Ltd., United Kingdom). Hundred microliter of this homogenate were then added to $10 \mathrm{ml}$ of CM-GM17 supplemented with cycloheximide $(20 \mu \mathrm{g} / \mathrm{ml})$ to inhibit yeast and mold growth, and inoculated into $100 \mathrm{ml}$ of an overnight culture of single different host E. faecalis strains (Table 1). Enrichment cultures were incubated for $24 \mathrm{~h}$. Samples were then centrifuged $(2000 \times g$ for $15 \mathrm{~min})$ in a 5810 Eppendorf benchtop centrifuge, and $100 \mu \mathrm{l}$ of the resulting supernatant used to inoculate $(1 \% \mathrm{v} / \mathrm{v})$ a new enrichment culture. After two rounds of enrichment, $10 \mu \mathrm{l}$ were spotted onto double-layered agar CMGM17 plates and incubated for $24 \mathrm{~h}$ at $30^{\circ} \mathrm{C}$. If an inhibition halo was observed, the source supernatant was streaked to obtain single plaques. If differences in the morphology of the plaques, such as size or turbidity, were observed, host range comparisons were performed to see whether different phages were present. Phages from different host strain enrichment cultures, but from the same cheese sample, that showed an identical host range, were considered isolates of the same phage. However, if differences in the host range were observed, they were considered different phages. For bacteriophage purification, a single plaque was picked up with a sterile tip, inoculated into $50 \mathrm{ml}$ of CM-GM17 broth containing the host strain, and incubated at $30^{\circ} \mathrm{C}$ until cell lysis was observed. The culture was then spun $(10,000 \times g$ for $15 \mathrm{~min})$ in a 7780 centrifuge (Kubota, South Korea) with an AG6512C rotor, concentrated using the PEG/NaCl method (Binetti et al., 2005), and stored for further analysis.

\section{Microbiological Assays}

The host range of the isolated phages was determined by challenging them against 27 E. faecalis strains of different origin (Table 2 and Supplementary Table 1). A $10 \mu \mathrm{l}$ drop of phage suspension was placed on double-layered agar CM-GM17 plates containing the different potential host strains as previously described (del Rio et al., 2019b).

\section{Electron Microscopy}

Concentrated particles of selected phages were purified in a continuous $\mathrm{CsCl}$ gradient by centrifugation $(100,000 \times g$ for $20 \mathrm{~h}$ at $4^{\circ} \mathrm{C}$ ) in an Optimax ultracentrifuge (Beckman Coulter, United States), as described by Gutierrez et al. (2011). Purified phage particles were stained with $2 \%$ uranyl acetate solution and electron micrographs produced using a CCD Gatan Erlangshen ES $1000 \mathrm{~W}$ camera coupled to a JEOL JEM 1011 transmission electron microscope (JEDL USA Inc, United States) operated at $100 \mathrm{kV}$ (performed at the Electron Microscopy Service of the Biotechnology National Centre [CNB-CSIC], Spain).

\section{Phage DNA Extraction}

Phage DNA was obtained from a concentrated suspension of phage particles as previously described (del Rio et al., 2019b). Briefly, $80 \mu \mathrm{l}$ of lysis solution (0.25 M EDTA, pH 8.1; $0.5 \mathrm{M}$ Tris-HCl, $\mathrm{pH}$ 9.6; $2.5 \%$ sodium dodecyl sulfate) were added to $400 \mu \mathrm{l}$ of phage suspension and incubated in a water bath at $65^{\circ} \mathrm{C}$ for $30 \mathrm{~min}$. Hundred microliter of $8 \mathrm{M}$ potassium acetate were then added, and the mixture incubated on ice for $15 \mathrm{~min}$ and further centrifuged $\left(16,000 \times g, 10 \mathrm{~min}\right.$, at $\left.4^{\circ} \mathrm{C}\right)$ in a 5415R Eppendorf centrifuge. Phage DNA was precipitated from the supernatant with one volume of isopropanol, kept at room temperature for $5 \mathrm{~min}$, and centrifuged again $(16,000 \times g, 10 \mathrm{~min}$ at room temperature). The pellet was resuspended in TE buffer (10 mM Tris-HCl, $1 \mathrm{mM} \mathrm{EDTA,} \mathrm{pH}$ 8.0) in the presence of $0.3 \mathrm{M}$ sodium acetate $\mathrm{pH} 4.8$, and precipitated twice with isopropanol for $5 \mathrm{~min}$, followed by centrifugation $(16,000 \times g, 10 \mathrm{~min}$ at room temperature). The DNA pellet was then washed with absolute ethanol and 70\% ethanol before being resuspended in TE buffer.

\section{Whole Genome Sequencing and Annotation}

A genomic library of $0.5 \mathrm{kbp}$ was constructed and subjected to 150 paired-end sequencing (providing approximately 800fold coverage) using a HiSeq 1000 System sequencer (Illumina) at GATC Biotech (Germany). Quality filtered reads were 
assembled using SPADES software ${ }^{1}$ (Bankevich et al., 2012). For vB_EfaS_159, a second library was constructed using fragments generated after HindIII digestion of the genomic DNA. Both libraries were combined in the assembly using SPADES software. The genomic sequence was closed by Sanger sequencing (performed at Macrogen, Spain) after PCR amplification following previously described procedures (Perez et al., 2015). Annotation was performed using the RAST server $^{2}$ (Aziz et al., 2008), improving it with results obtained from BLAST analysis ${ }^{3}$ (Altschul et al., 1997). The genome sequences obtained were deposited at the European Nucleotide Archive (ENA) under accession numbers CAJCJZ010000002.1 (140), CAJDJZ010000002.1 (149), CAJDKF010000002.1 (159), and CAJDJX010000002.1 (Q69).

\section{Phylogenetic Analysis}

A phylogenetic analysis of complete E. faecalis bacteriophage genome sequences available in the NCBI database (Supplementary Table 2) was performed using the Neighbor joining method following genome nucleotide sequence alignment undertaken employing MAFFT v.7 software (Katoh et al., 2019). All genomic sequences were edited to start at the terminase, or at the major capsid genes if no terminase gene was identified. A second phylogenetic analysis was performed aligning the amino acidic sequence of the major capsid protein of the same phages by the unweighted pair group method with arithmetic means (UPGMA) using MAFFT v.7 software (Katoh et al., 2019). The trees were visualized in iTOL ${ }^{5}$ (Letunic and Bork, 2016).

\section{RESULTS}

\section{Bacteriophage Screening}

A total of 60 retail cheese samples from different geographical origin purchased at different markets in Asturias (Spain) and with different technological characteristics were screened for the presence of E. faecalis infecting phages. After two rounds of enrichment culture, a drop of the supernatant was deposited on CM-GM17 agar plates and covered, individually, with the host strains used in enrichment. A growth inhibition halo was deemed to indicate the potential presence of a phage. Likely phage-positive supernatants were then streaked onto the plates, covered with the same inhibited strains, following the doublelayered agar CM-GM17 method to check for the appearance of isolated lysis plaques. A single plaque was used to propagate and store phages for further characterization. Twenty-two E. faecalisinfecting phages were isolated from 15 cheese samples, i.e., $25 \%$ of the samples screened. In at least five samples, more than one phage was isolated (data not shown). The cheeses returning the most phage-positive results were Zamorano, Boffard, and Cabrales, the latter two accounting for $60 \%$ of all those isolated.

\footnotetext{
${ }^{1}$ http://cab.spbu.ru/software/spades/

${ }^{2}$ http://rast.nmpdr.org/rast.cgi

${ }^{3}$ http://blast.ncbi.nlm.nih.gov

${ }^{4}$ https://mafft.cbrc.jp/alignment/server/

${ }^{5}$ https://itol.embl.de/
}

Two of the isolated phages -156 and Q69- have been previously described (Ladero et al., 2016a; del Rio et al., 2019b) and have been included in this work for further characterization and comparison.

\section{Bacteriophage Host Range}

To determine and compare the host ranges of the isolated phages, the battery of E. faecalis strains tested was increased to 27 to include those of meat and human origin (Table 2). All were challenged with the 22 phages using the spot test. If a clear halo was observed, the strain was considered sensitive to that phage. Phages 140,148, 149, and 157 showed the widest host ranges, infecting more than $50 \%$ of the strains tested. Among the other phages, eight infected between 25 and 50\% of the strains, and eight infected $<25 \%$ (Table 3 and Supplementary Table 1). It is noteworthy that phage 157 infected $75 \%$ of the strains challenged, while phages 142 and 155 infected just one strain. E. faecalis type strain CECT481 ${ }^{\mathrm{T}}$ was among the most sensitive of strains, together with two strains of human origin (infected by $>70 \%$ of the tested phages). Although the screened samples were from dairy environments, only seven phages were able to infect $>50 \%$ of the tested E. faecalis dairy strains. Only two phages were able to infect $>50 \%$ of the challenged strains of human origin. None of the phages were able to infect the two strains of meat origin, while at least five phages infected the two strains of clinical origin (Table 3).

\section{Bacteriophage Morphology}

In addition to the previously characterized phages -156 and Q69-, we have selected three additional phages -140, 149, and 159- showing functional or differential structural traits for more in-depth characterization. Phage 140 was selected to further investigate the underlying genetic causes that make its genome resistant to cleavage by several restriction enzymes. Regarding phages 149 and 159, they were selected since the former had one of the largest host ranges (Table 3 and Supplementary Table 1) and the latter, the larger plaque size among the phages analyzed in this work (data not shown).

Morphology of phage Q69 has been reported previously (Ladero et al., 2016a), showing it to belong to the family Siphoviridae. Phage 156 was previously classified as a member of the Myoviridae family (del Rio et al., 2019b), but it has been reclassified as a member of Herelleviridae, genus Kochikohdavirus (Barylski et al., 2020).

The morphology of phage 149 showed the characteristics typical of myoviruses, i.e., an icosahedral head with a non-flexible contractile tail (Figure 1A). The head diameter was estimated at $75 \pm 3 \mathrm{~nm}$, the contracted tail sheath at $114 \pm 5 \mathrm{~nm}$, and the visible section of the tail tube at $69 \pm 4 \mathrm{~nm}$, indicating an estimated tail length of $184 \pm 6 \mathrm{~nm}$. A neck and a baseplate were also clearly observed (Figure 1A). Based on phage 149's genome (see next section) and its strong similarity with phage 156 and other genomes of Kochikohdavirus members, it is proposed here to be a member of the family Herelleviridae. Its proposed name following the International Committee on Taxonomy of Viruses (ICTV) recommendations is vB_EfaH_149. 


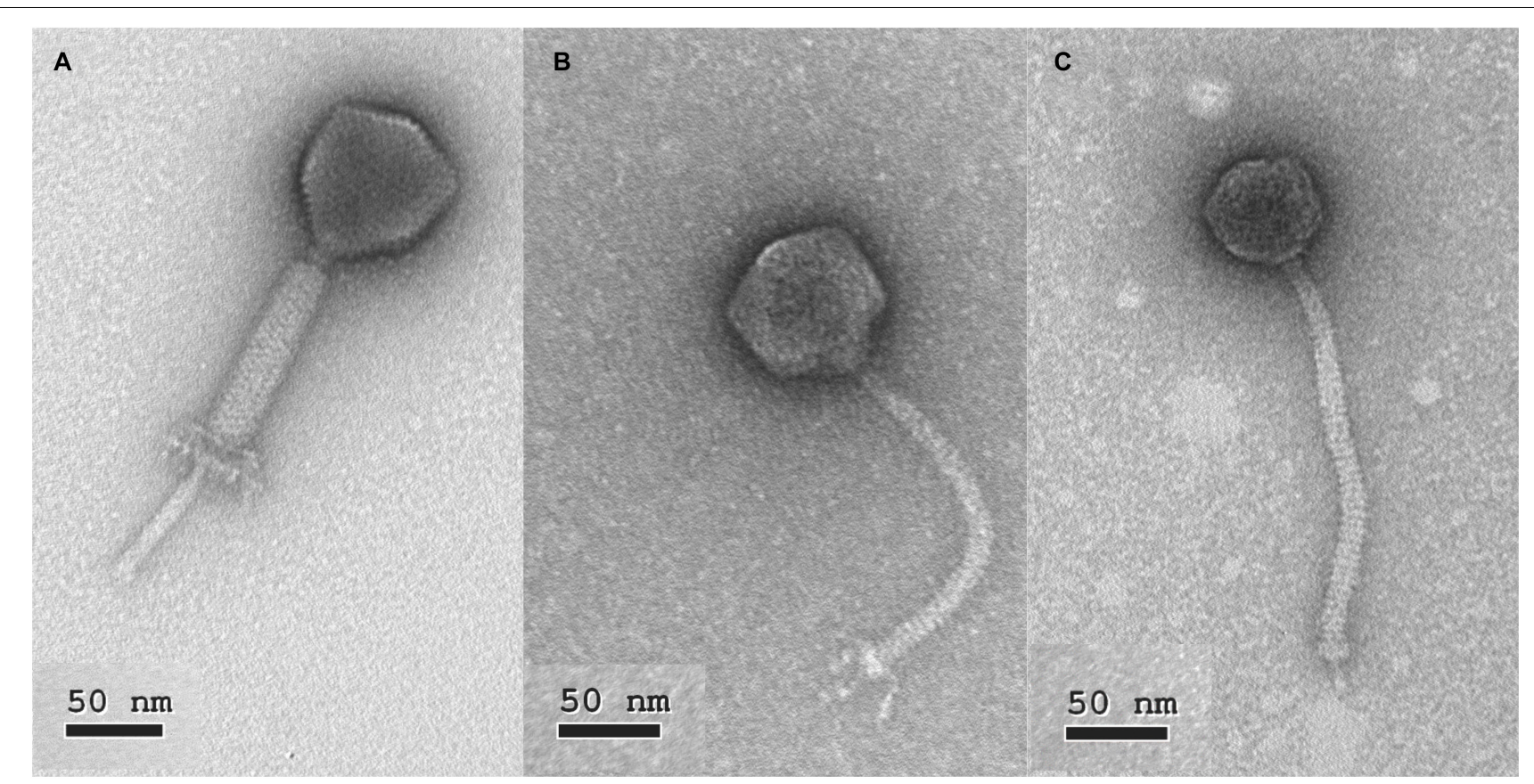

FIGURE 1 | Electron photomicrographs of selected phages. (A) vB_EfaH149, (B) vB_EfaS_140, (C) vB_EfaS_159.

The observed morphology of phage 140 showed it to belong to this same family: head diameter $71 \pm 3 \mathrm{~nm}$, flexible tail $172 \pm 5 \mathrm{~nm}$ long, and a base plate with some accessory decorating proteins (Figure 1B). Based on these characteristics and following the ICTV recommendations it is here proposed that it be named vB_EfaS_140.

The morphology of phage 159 (Figure 1C) (tail length $190 \pm 3 \mathrm{~nm}$, the head diameter $57 \pm 4 \mathrm{~nm}$, baseplate and a clearly observable spike) indicates it to also belong to the family Siphoviridae. It is here proposed it be named vB_EfaS_159 following the ICTV recommendations.

\section{Bacteriophage Genomes}

The genomes of the selected phages 140 (vB_EfaS_140), 149 (vB_EfaH_149), and 159 (vB_EfaS_159), plus that of Q69, were sequenced and characterized. Their $\mathrm{G}+\mathrm{C}$ content ranged from $30.2 \%$ for phage vB_EfaS_140 to 36\% for phage vB_EfaH_149, both below the $\mathrm{G}+\mathrm{C}$ content of the $E$. faecalis host species (estimated at $37.4 \%$ ).

The genome of phage vB_EfaH_149 was shown to be a dsDNA molecule of 142,215 bp with 193 open reading frames and six $t R N A$ genes coding for sequences carrying the codons TGT, CAT, TGG, TCT, CCA and GTC (for threonine, methionine, proline, arginine, tryptophan, and aspartate respectively). Only $18 \%$ of the open reading frames coded for an identifiable function, all related to replication, packaging, capsid formation and lysis (Figure 2 and Supplementary Table 3a). The genome showed strong similarity (data not shown) to that of the previously sequenced phage 156, which consists of a 141,133 bp-long dsDNA molecule comprising 209 open reading frames and $5 t R N A$ genes (del Rio et al., 2019b).
Although phage Q69 has been previously described (Ladero et al., 2016a), its genome was not characterized and thus it was sequenced in this work. Q69 genome consist in a dsDNA molecule 42,241 bp long with 71 open reading frames. For $43 \%$ of these, a putative function was assigned - the largest proportion of functional assignments for all five genomes analyzed. The putative functions assigned were related to head, neck, and tail structural proteins, and replicative functions. In addition, a putative holin- and lysin- coding genes were found (Figure 2 and Supplementary Table $\mathbf{3 b}$ ). The arrangement of the genes in the genome map revealed two divergently transcribed regions organized as functional modules (Figure 2).

The genome of phage vB_EfaS_140 was found to be a dsDNA molecule of $85,454 \mathrm{pb}$ comprising 129 open reading frames and a $t R N A$ gene coding for the CCA codon (the codon for tryptophan). A putative function could be assigned to only $25 \%$ of the open reading frames found, with functions related to replication, packaging, capsid formation and lysis (Figure 2 and Supplementary Table 3c). Among those genes for which a putative function was determined, some coded for enzymes related to nucleotide modification, such as CDS_73 coding for a putative DNA beta-glucosyltransferase similar to that of Escherichia coli phage T4 (Blastp E value 2e-75), which might be related to the observed refraction of its genomic DNA to enzymatic restriction with several tested nucleases (data not shown).

Finally, the genome of phage vB_EfaS_159 was also found to be a dsDNA molecule, 41,718 bp long, with 69 open reading frames. Putative functions involving replication, packaging, capsid formation and lysis functions were assigned to $34 \%$ of them (Figure 2 and Supplementary Table 3d). 


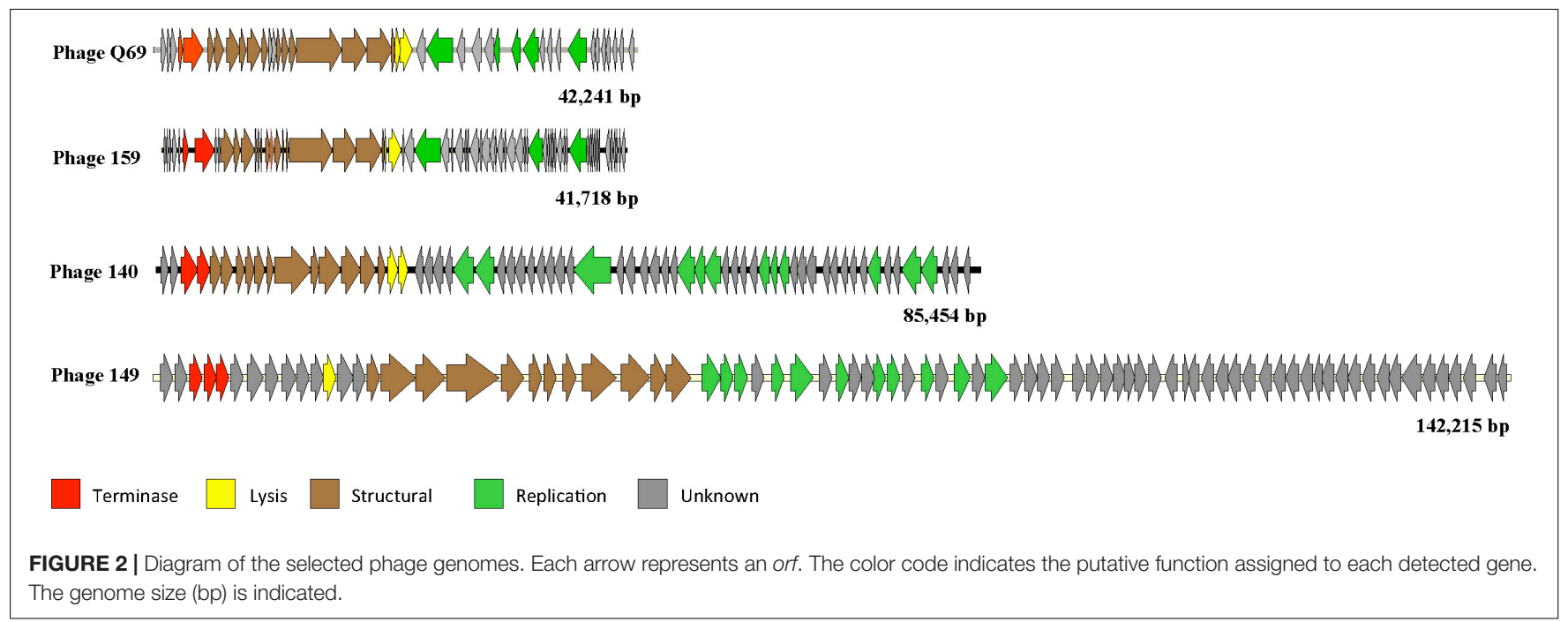

No gene in any of the analyzed genomes was identified as toxin-encoding. Nor was any related to antibiotic resistance or any other pathogenic trait.

\section{Phylogenetic Relatedness of Bacteriophages}

To study the diversity of the four sequenced genomes, a phylogenetic tree was constructed based on their alignment with the full genomes of E. faecalis-infecting phages available in the NCBI database (Figure 3 and Supplementary Table 2); this included the previously published 156 genome. The diversity of the database-available genomes was wide. Most of them grouped according to their taxonomic classification, although several discrepancies can be observed (Figure 3). The vB_EfaS_140 genome did not group with any of the other phage genomes from the present work, but did so with other E. faecalis-infecting phage genomes, all of which share the characteristic of being among the largest genomes of the Siphoviridae group (>85 kbp). The genomes of phages vB_EfaH_149 and 156 were closely related, as were those of Q69 and vB_EfaS_159.

In further analysis, the major capsid proteins of the three selected phages plus 156 and Q69 were aligned with those of the E. faecalis-infecting phages available in the NCBI database (Figure 4 and Supplementary Table 2). The phylogenetic tree generated reflects the described taxonomy of the E. faecalisinfecting phages, which groups them into three families Herelleviridae, Podoviridae and Siphoviridae- but also into subfamilies and genera (Supplementary Table 2). Some phages annotated as unclassified in the NCBI database (Supplementary Table 2) clustered with well described groups, indicating them to share common characteristics (Figure 4). Q69, shown in the NCBI database to be an unclassified Siphoviridae phage, grouped with phages belonging to the genus Efquatrovirus. Phage vB_EfaS_159, which is close to Q69, was also associated with members of Efquatrovirus. Phage vB_EfaS_140 grouped with the phages vipetofem and nattely, both unclassified Siphoviridae phages. All three share the characteristic of having the largest genomes among the E. faecalis-infecting Siphoviridae described (>80 kbp long). Phage vB_EfaH_149 grouped with family Herelleviridae genus Kochikohdavirus phages. The Kochikohdavirus genus comprises a group of phages, the genomes of which, show strong similarity. A high degree of homology was observed between the vB_EfaH_149 and 156 genomes indicating vB_EfaH_149 to be a new member of this genus.

\section{DISCUSSION}

Biogenic amine are toxic compounds that can accumulate by the microbial action at elevated concentrations in foodstuffs, especially in fermented food products such as cheese. In the particular case of cheese -one of the foods in which higher concentrations of BA can be found (EFSA, 2011)- the microorganisms responsible of $\mathrm{BA}$ accumulation are members of the LAB group (Ladero et al., 2016b), which play an essential role in the fermentation and determination of the organoleptic characteristics of the mature cheese (Beresford and Williams, 2004). This dual role implies that specific measures targeting BA-producing microorganisms without affecting the other LAB present in the cheese matrix must be adopted to ensure the quality and final organoleptic characteristics, but maintaining food safety for consumers. Among them, phage biocontrol has arisen as a promising biotechnological alternative (Garcia et al., 2008; Ladero et al., 2016a; Yamaki et al., 2018). In fact, two of the bacteriophages compared in this work, 156 and Q69, were successfully assayed in an experimental cheese model for the reduction of the final content in tyramine and putrescine -the BA most frequently found in cheeses- which are mainly produced by E. faecalis (Fernández et al., 2007; Ladero et al., 2016a; del Rio et al., 2019b). One of the problems that phage biocontrol must face to be applied to $\mathrm{LAB}$ is the narrow host range of the phages that infect bacteria of this group (Kot et al., 2014; Martínez et al., 2016). To overcome this problem, one of the solutions is to use phages cocktails instead of single phages (Chan et al., 2013; Bolocan et al., 2019). A requisite to design adequate phage 


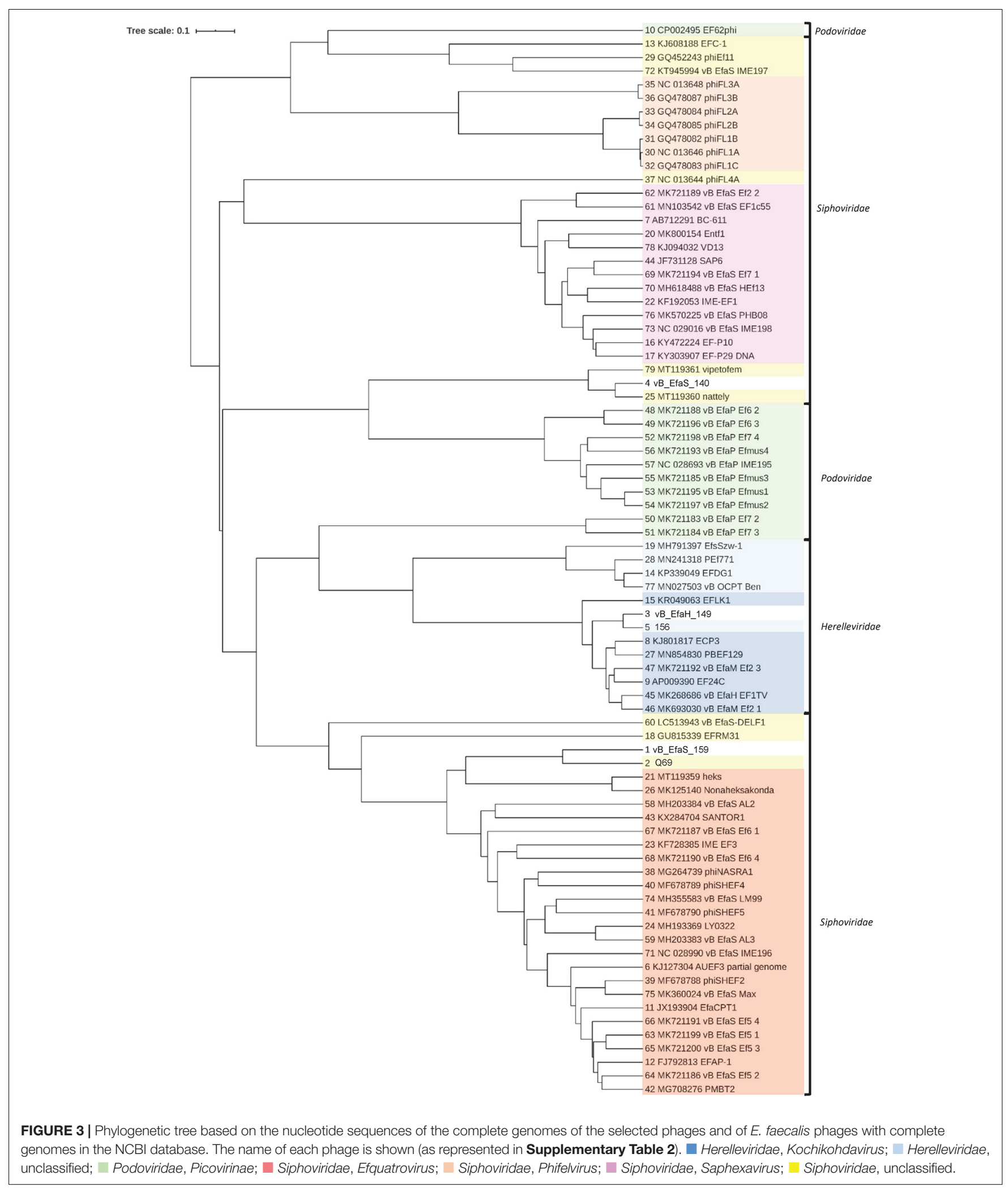

cocktails targeting the large diversity of strains that can be found in a rich non-sterile matrix as milk, is to have a large collection of well characterized phages with different host ranges.
The cheeses made from raw milk provided the largest number of different phages (Table 1) (but note that some types of cheese were more extensively sampled than others). This is to 
Tree scale: $0.1 \longmapsto$

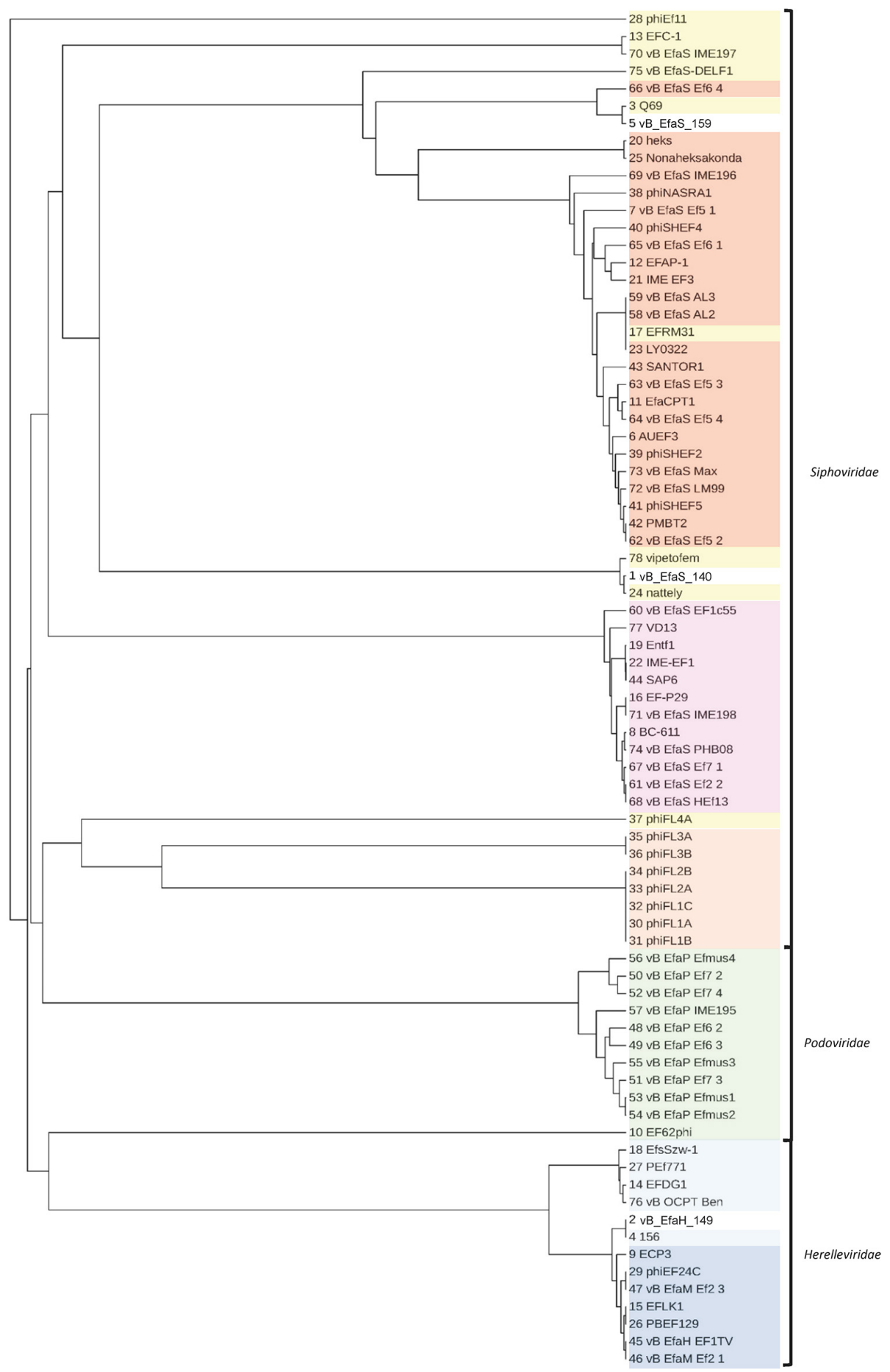

FIGURE 4 | Phylogenetic tree based on the amino acid sequence of the major head proteins of the selected phages and of E. faecalis phages with complete genomes in the NCBI database. The name of each phage is shown (as represented in Supplementary Table 2). $\mathbf{H}$ Herelleviridae, Kochikohdavirus; $\square$ Herelleviridae,

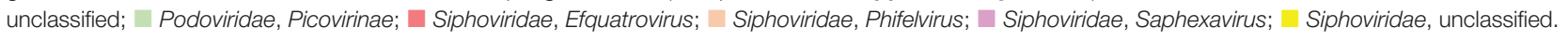

be expected since cheeses made from raw milk have a greater diversity of microorganisms, especially of secondary microbiota such as enterococci, including E. faecalis (Gobbetti et al., 2018).
Only five phages were able to infect more than half of the strains challenged (Table 3). Among them, phage vB_EfaH_149 showed typical myovirus morphology, and belongs to the new 
TABLE 3 | Host range of the isolated phages.

\begin{tabular}{|c|c|c|c|c|c|c|c|}
\hline \multirow[b]{2}{*}{ Phage } & \multirow[b]{2}{*}{ Plaque size } & \multicolumn{5}{|c|}{ E. faecalis strain origin } & \multirow[b]{2}{*}{ Total $(n=27)$} \\
\hline & & Type $(n=1)$ & Dairy $(n=14)$ & Meat $(n=2)$ & Human $(n=8)$ & Clinical $(n=2)$ & \\
\hline 141 & ++ & 1 & 6 & 0 & 2 & 0 & 9 \\
\hline 142 & + & 0 & 0 & 0 & 1 & 0 & 1 \\
\hline 143 & + & 0 & 1 & 0 & 3 & 2 & 6 \\
\hline 146 & ++ & 0 & 1 & 0 & 1 & 2 & 4 \\
\hline 147 & ++ & 0 & 1 & 0 & 3 & 2 & 6 \\
\hline 148 & + & 1 & 12 & 1 & 2 & 1 & 17 \\
\hline 149 & + & 1 & 12 & 1 & 2 & 1 & 17 \\
\hline 150 & ++ & 1 & 6 & 0 & 2 & 1 & 10 \\
\hline 156 & + & 1 & 13 & 1 & 3 & 2 & 20 \\
\hline 157 & + & 1 & 13 & 1 & 3 & 2 & 20 \\
\hline 158 & +++ & 1 & 7 & 0 & 2 & 0 & 10 \\
\hline 159 & +++ & 1 & 6 & 0 & 2 & 0 & 9 \\
\hline 160 & +++ & 1 & 7 & 0 & 2 & 0 & 10 \\
\hline 161 & +++ & 1 & 6 & 0 & 0 & 0 & 7 \\
\hline Q69 & ++ & 1 & 6 & 0 & 3 & 0 & 10 \\
\hline
\end{tabular}

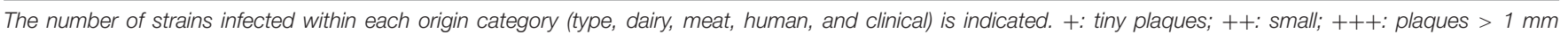
diameter.

Herelleviridae family, the phages of which usually show wider host ranges than Siphoviridae phages. No clear relationship was seen between the origin of the phages and the origin of the E. faecalis strains they infected. It might be expected that the dairy phages vB_EfaH_149 and 156 would preferentially infect E. faecalis strains of dairy origin (Table 3). The more E. faecalis strains a particular phage can infect, the greater the diversity of host origin. Interestingly, some of the isolated phages were able to infect clinical E. faecalis strains, including AMR strains (Table 3). Thus, they may be worth investigating as phage therapy agents. A large proportion of the isolated phages were unable to infect half of the strains tested, regardless of their origin. However, this is not surprising since the phages already known to infect $\mathrm{LAB}$ species are reported to have a narrow host range (Kot et al., 2014; Martínez et al., 2016). Since several of these belong to different families (or even genera) and have different host ranges, the selection of an adequate combination would improve the range of E. faecalis strains against which a cocktail could be effective (Chan et al., 2013).

Phage 156 was previously classified as a member of Myoviridae (del Rio et al., 2019b), but the ICTV recently published a new family classification of the order Caudovirales (Adriaenssens et al., 2020). As a result, phage 156 was reclassified as a member of the family Herelleviridae, subfamily Brockvirinae, genus Kochikohdavirus. Phage vB_EfaH_149 should be classified within the same genus given the homology found with phage 156 and other members of this genus (Figure 3). Similarly, phages Q69 and vb_EfaS_159 might be proposed new members of the genus Efquatrovirus. Based on its morphology, phage Q69 was previously designated as an unclassified Siphoviridae phage (Ladero et al., 2016a), but the determination of its genome sequence and its observed similarity with the genomes of other members of that genus, suggest it should be reclassified. Phage vB_EfaS_140 was found to be closely related to the Enterococcus-infecting Siphoviridae phages that possess a large genome of $>80 \mathrm{kbp}$, while the majority of phage genomes belonging to this group are around $30-40 \mathrm{kbp}$ long or shorter. Further investigation into the taxonomy and relationship of these phages with other large-genome Siphoviridae phages should be performed before they are assigned a taxonomic classification.

Enterococcus-infecting phages are traditionally screened in sewage water attending to the consideration of Enterococcus as member of the fecal microbiota. However, the members of Enterococcus genus are found in many environments, and are particularly common in foods of animal origin such as cheese. The phages described in the present work were distributed at different positions within the phylogenetic tree, and interspaced with phages isolated from other environments. Moreover, most were shown able to infect $E$. faecalis strains of non-dairy origin, including human (mostly fecal) and multiresistant strains from clinical environments. Genome analysis revealed the absence of virulence-related and antibiotic resistance genes in the studied genomes - essential safety features for their use in food or health applications. In summary, the present results increase the number of phages that might be used in cocktails to control E. faecalis in fermented foods, in which it may cause the 
accumulation of BAs, and perhaps in the clinical setting to fight against multiresistant enterococci.

\section{DATA AVAILABILITY STATEMENT}

The datasets presented in this study can be found in online repositories. The names of the repository/repositories and accession number(s) can be found below: https://www.ncbi.nlm. nih.gov/genbank/, CAJCJZ010000002.1; https://www.ncbi.nlm. nih.gov/genbank/, CAJDKF010000002.1; https://www.ncbi.nlm. nih.gov/genbank/, CAJDJX010000002.1; https://www.ncbi.nlm. nih.gov/genbank/, CAJDJZ010000002.1.

\section{AUTHOR CONTRIBUTIONS}

$\mathrm{BR}$ and VL designed and carried out some of the experiments and drafted the manuscript. ES-L and NM participated in the screening and phage characterization. BR, VL, and MF participated in the design of the study and helped write the manuscript. MA provided the general concept and supervised the work and the writing of the manuscript. All authors contributed to the discussions surrounding the work and approved the final version of the manuscript.

\section{REFERENCES}

Adriaenssens, E. M., Sullivan, M. B., Knezevic, P., van Zyl, L. J., Sarkar, B. L., Dutilh, B. E., et al. (2020). Taxonomy of prokaryotic viruses: 2018-2019 update from the ICTV Bacterial and Archaeal Viruses Subcommittee. Arch. Virol. 165, 1253-1260. doi: 10.1007/s00705-020-04577-8

Altschul, S. F., Madden, T. L., Schaffer, A. A., Zhang, J., Zhang, Z., Miller, W., et al. (1997). Gapped BLAST and PSI-BLAST: a new generation of protein database search programs. Nucl. Acids Res. 25, 3389-3402. doi: 10.1093/nar/25.17.3389

Aziz, R. K., Bartels, D., Best, A. A., DeJongh, M., Disz, T., Edwards, R. A., et al. (2008). The RAST Server: rapid annotations using subsystems technology. BMC Genom. 9:75. doi: 10.1186/1471-2164-9-75

Bankevich, A., Nurk, S., Antipov, D., Gurevich, A. A., Dvorkin, M., Kulikov, A. S., et al. (2012). SPAdes: a new genome assembly algorithm and its applications to single-cell sequencing. J. Comput. Biol. 19, 455-477. doi: 10.1089/cmb.2012. 0021

Barylski, J., Kropinski, A. M., Alikhan, N.-F., Adriaenssens, E. M., and Ictv Report Consortium. (2020). ICTV Virus Taxonomy Profile: herelleviridae. J. Gen. Virol. 101, 362-363. doi: 10.1099/jgv.0.001392

Beresford, T., and Williams, A. (2004). "The microbiology of cheese ripening," in Cheese Chemistry, Physics and Microbiology, eds P. F. Fox, P. L. H. McSweeney, T. M. Cogan, and T. P. Guinee (Amsterdam: Elsevier), 287-317.

Binetti, A. G., del Rio, B., Martin, M. C., and Alvarez, M. A. (2005). Detection and characterization of Streptococcus thermophilus bacteriophages by use of the antireceptor gene sequence. Appl. Environ. Microbiol. 71, 6096-6103. doi: 10.1128/Aem.71.10.6096-6103.2005

Bolocan, A. S., Upadrasta, A., Bettio, P. H. A., Clooney, A. G., Draper, L. A., Ross, R. P., et al. (2019). Evaluation of phage therapy in the context of Enterococcus faecalis and its associated diseases. Viruses 11:366. doi: 10.3390/v1104 0366

Chan, B. K., Abedon, S. T., and Loc-Carrillo, C. (2013). Phage cocktails and the future of phage therapy. Fut. Microbiol 8, 769-783. doi: $10.2217 / \mathrm{fmb} .13 .47$

del Rio, B., Redruello, B., Ladero, V., Cal, S., Obaya, A. J., and Alvarez, M. A. (2018). An altered gene expression profile in tyramine-exposed intestinal cell cultures supports the genotoxicity of this biogenic amine at dietary concentrations. Sci. Rep. 8:17038. doi: 10.1038/s41598-018-35125-9

\section{FUNDING}

This work was funded by the Spanish Ministry of Economy and Competitiveness through the State Research Agency (AEI) (AGL2016-78708-R; AEI/FEDER, UE), CSIC (CSIC201770E086 and CSIC201870I091), by the Government of the Principality of Asturias through the PCTI, and by the European Regional Development Funds (IDI/2018/000114; FEDER, UE).

\section{ACKNOWLEDGMENTS}

The authors are grateful to the Electron Microscopy Service at the National Biotechnology Centre (CNB-CSIC) for taking the electron photomicrographs. The authors thank Adrian Burton for language and editing assistance.

\section{SUPPLEMENTARY MATERIAL}

The Supplementary Material for this article can be found online at: https://www.frontiersin.org/articles/10.3389/fmicb. 2020.592172/full\#supplementary-material

del Rio, B., Redruello, B., Linares, D. M., Ladero, V., Ruas-Madiedo, P., Fernandez, M., et al. (2019a). The biogenic amines putrescine and cadaverine show in vitro cytotoxicity at concentrations that can be found in foods. Sci. Rep. 9:120. doi: 10.1038/s41598-018-36239-w

del Rio, B., Sanchez-Llana, E., Redruello, B., Magadan, A. H., Fernandez, M., Martin, M. C., et al. (2019b). Enterococcus faecalis bacteriophage 156 Is an effective biotechnological tool for reducing the presence of tyramine and putrescine in an experimental cheese model. Front. Microbiol. 10:566. doi: 10. 3389/fmicb.2019.00566

EFSA (2011). Scientific Opinion on risk based control of biogenic amine formation in fermented foods. EFSA Panel on Biological Hazards (BIOHAZ). EFSA J. 9, 2393-2486.

Fernandez, L., Escobedo, S., Gutierrez, D., Portilla, S., Martinez, B., Garcia, P. et al. (2017). Bacteriophages in the dairy environment: from enemies to allies. Antibiotics 6:27. doi: 10.3390/antibiotics6040027

Fernández, M., Linares, D. M., del Río, B., Ladero, V., and Alvarez, M. A. (2007). HPLC quantification of biogenic amines in cheeses: correlation with PCRdetection of tyramine-producing microorganisms. J. Dairy Res. 74, 276-282. doi: 10.1017/S0022029907002488

Foulquie Moreno, M. R., Sarantinopoulos, P., Tsakalidou, E., and De Vuyst, L. (2006). The role and application of enterococci in food and health. Int. J. Food Microbiol. 106, 1-24. doi: 10.1016/j.ijfoodmicro.2005.06.026

Garcia, P., Martinez, B., Obeso, J. M., and Rodriguez, A. (2008). Bacteriophages and their application in food safety. Lett. Appl. Microbiol. 47, 479-485. doi: 10.1111/j.1472-765X.2008.02458.x

Giard, J. C., Hartke, A., Flahaut, S., Benachour, A., Boutibonnes, P., and Auffray, Y. (1996). Starvation-induced multiresistance in Enterococcus faecalis JH2-2. Curr. Microbiol. 32, 264-271. doi: 10.1007/s002849900048

Giraffa, G. (2003). Functionality of enterococci in dairy products. Int. J. Food Microbiol. 88, 215-222. doi: 10.1016/S0168-1605(03)00183-1

Gobbetti, M., Di Cagno, R., Calasso, M., Neviani, E., Fox, P. F., and De Angelis, M. (2018). Drivers that establish and assembly the lactic acid bacteria biota in cheeses. Trends Food Sci. Technol. 78, 244-254. doi: 10.1016/j.tifs.2018. 06.010

Gutierrez, D., Martin-Platero, A., Rodriguez, A., Martinez-Bueno, M., Garcia, P., and Martinez, B. (2011). Typing of bacteriophages by randomly amplified 
polymorphic DNA (RAPD)-PCR to assess genetic diversity. Fems Microbiol. Lett. 322, 90-97. doi: 10.1111/j.1574-6968.2011.02342.x

Hesse, S., and Adhya, S. (2019). Phage therapy in the twenty-first century: facing the decline of the antibiotic era; Is it finally time for the age of the phage? Annu. Rev. Microbiol. 73, 155-174. doi: 10.1146/annurev-micro-090817-62535

Katoh, K., Rozewicki, J., and Yamada, K. D. (2019). MAFFT online service: multiple sequence alignment, interactive sequence choice and visualization. $B r$. Bioinform. 20, 1160-1166. doi: 10.1093/bib/bbx108

Khan, H., Flint, S., and Yu, P. L. (2010). Enterocins in food preservation. Int. J. Food Microbiol. 141, 1-10. doi: 10.1016/j.ijfoodmicro.2010.03.005

Kot, W., Neve, H., Heller, K. J., and Vogensen, F. K. (2014). Bacteriophages of leuconostoc, oenococcus, and weissella. Front. Microbiol. 5:186. doi: 10.3389/ fmicb.2014.00186

Ladero, V., Calles-Enríquez, M., Fernández, M., and Alvarez, M. A. (2010a). Toxicological effects of dietary biogenic amines. Curr. Nutr. Food Sci. 6, 145156. doi: 10.2174/157340110791233256

Ladero, V., Canedo, E., Perez, M., Cruz Martin, M., Fernandez, M., and Alvarez, M. A. (2012a). Multiplex qPCR for the detection and quantification of putrescine-producing lactic acid bacteria in dairy products. Food Control. 27, 307-313. doi: 10.1016/j.foodcont.2012.03.024

Ladero, V., Fernandez, M., and Alvarez, M. A. (2009). Isolation and identification of tyramine-producing enterococci from human fecal samples. Can. J. Microbiol. 55, 215-218. doi: 10.1139/W08-133

Ladero, V., Fernandez, M., Calles-Enriquez, M., Sanchez-Llana, E., Canedo, E., Martin, M. C., et al. (2012b). Is the production of the biogenic amines tyramine and putrescine a species-level trait in enterococci? Food Microbiol. 30, 132-138. doi: 10.1016/J.Fm.2011.12.016

Ladero, V., Fernandez, M., Cuesta, I., and Alvarez, M. A. (2010b). Quantitative detection and identification of tyramine-producing enterococci and lactobacilli in cheese by multiplex qPCR. Food Microbiol. 27, 933-939. doi: 10.1016/J.Fm. 2010.05.026

Ladero, V., Gomez-Sordo, C., Sanchez-Llana, E., del Rio, B., Redruello, B., Fernandez, M., et al. (2016a). Q69 (an E. faecalis-Infecting bacteriophage) as a biocontrol agent for reducing tyramine in dairy products. Front. Microbiol. 7:445. doi: 10.3389/Fmicb.2016.00445

Ladero, V., Linares, D. M., Pérez, M., del Rio, B., Fernández, M., and Alvarez, M. A. (2016b). "Biogenic Amines in Dairy Products," in Microbial Toxins in Dairy Products. Hoboken, NJ: Wiley Blackwell, 94-131. doi: 10.1002/9781118823095. ch4

Ladero, V., Sanchez-Llana, E., Fernandez, M., and Alvarez, M. A. (2011). Survival of biogenic amine-producing dairy LAB strains at pasteurisation conditions. Int. J. Food Sci. Technol. 46, 516-521. doi: 10.1111/j.1365-2621.2010.02508.x

Letunic, I., and Bork, P. (2016). Interactive tree of life (iTOL) v3: an online tool for the display and annotation of phylogenetic and other trees. Nucl. Acids Res. 44, W242-W245. doi: 10.1093/nar/gkw290

Linares, D. M., Cruz Martin, M., Ladero, V., Alvarez, M. A., and Fernandez, M. (2011). Biogenic amines in dairy products. Crit. Rev. Food Sci. Nutr. 51, 691-703. doi: 10.1080/10408398.2011.582813
Linares, D. M., del Rio, B., Redruello, B., Ladero, V., Martin, M. C., Fernandez, M., et al. (2016). Comparative analysis of the in vitro cytotoxicity of the dietary biogenic amines tyramine and histamine. Food Chem. 197, 658-663. doi: 10. 1016/j.foodchem.2015.11.013

Martínez, B., García, P., Gonzalez, A. R., Piuri, M., and Raya, R. R. (2016). "Bacteriophages of lactic acid bacteria and biotechnological tools," in Biotechnology of Lactic Acid Bacteria: Novel applications, eds F. Mozzi, R. R. Raya, and G. Vignolo (Chichester: JohnWiley \& Sons), 100-119.

Moye, Z. D., Woolston, J., and Sulakvelidze, A. (2018). Bacteriophage applications for food production and processing. Viruses 10:205. doi: 10.3390/v10040205

Novella-Rodriguez, S., Veciana-Nogues, M. T., Trujillo-Mesa, A. J., and VidalCarou, M. C. (2002). Profile of biogenic amines in goat cheese made from pasteurized and pressurized milks. J. Food Sci. 67, 2940-2944.

Ogier, J. C., and Serror, P. (2008). Safety assessment of dairy microorganisms: the Enterococcus genus. Int. J. Food Microbiol. 126, 291-301. doi: 10.1016/j. ijfoodmicro.2007.08.017

Paulsen, I. T., Banerjei, L., Myers, G. S., Nelson, K. E., Seshadri, R., Read, T. D., et al. (2003). Role of mobile DNA in the evolution of vancomycin-resistant Enterococcus faecalis. Science 299, 2071-2074. doi: 10.1126/science.1080613

Perez, M., Calles-Enriquez, M., Nes, I., Martin, M. C., Fernandez, M., Ladero, V., et al. (2015). Tyramine biosynthesis is transcriptionally induced at low $\mathrm{pH}$ and improves the fitness of Enterococcus faecalis in acidic environments. Appl. Microbiol. Biotechnol. 99, 3547-3558. doi: 10.1007/s00253-014-6301-7

Sillankorva, S. M., Oliveira, H., and Azeredo, J. (2012). Bacteriophages and their role in food safety. Int. J. Microbiol. 2012:863945. doi: 10.1155/2012/863945

Torres, C., Alonso, C. A., Ruiz-Ripa, L., Leon-Sampedro, R., Del Campo, R., and Coque, T. M. (2018). Antimicrobial Resistance in Enterococcus spp. of animal origin. Microbiol Spectr 6:ARBA0032-2018. doi: 10.1128/microbiolspec.ARBA0032-2018

Wunderlichová, L., Buòková, L., Koutn $\iota$, M., Janèová, P., and Buòka, F. (2014). Formation, degradation, and detoxification of putrescine by foodborne bacteria: a review. Compr. Rev. Food Sci. Food Saf. 13, 1012-1030. doi: 10.1111/15414337.12099

Yamaki, S., Kawai, Y., and Yamazaki, K. (2018). Biocontrol of Morganella morganii subsp. morganii and histamine accumulation in tuna meat by treatment with a lytic bacteriophage. Food Sci. Technol. Res. 24, 329-337. doi: 10.3136/fstr.24.329

Conflict of Interest: The authors declare that the research was conducted in the absence of any commercial or financial relationships that could be construed as a potential conflict of interest.

Copyright $\odot 2021$ del Rio, Sánchez-Llana, Martínez, Fernández, Ladero and Alvarez. This is an open-access article distributed under the terms of the Creative Commons Attribution License (CC BY). The use, distribution or reproduction in other forums is permitted, provided the original author(s) and the copyright owner(s) are credited and that the original publication in this journal is cited, in accordance with accepted academic practice. No use, distribution or reproduction is permitted which does not comply with these terms. 